\title{
Dualistic Forms
}

\section{Citation}

Rehding, Alexander. "Dualistic Forms." The Oxford Handbook of Neo-Riemannian Music Theories, ed. Edward Gollin and Alexander Rehding, 218-244. New York, NY: Oxford University Press, 2011.

\section{Published Version}

10.1093/oxfordhb/9780195321333.013.0007;doi:10.1093/oxfordhb/9780195321333.013.0007

\section{Permanent link}

http://nrs.harvard.edu/urn-3:HUL.InstRepos:37086279

\section{Terms of Use}

This article was downloaded from Harvard University's DASH repository, and is made available under the terms and conditions applicable to Other Posted Material, as set forth at http:// nrs.harvard.edu/urn-3:HUL.InstRepos:dash.current.terms-of-use\#LAA

\section{Share Your Story}

The Harvard community has made this article openly available.

Please share how this access benefits you. Submit a story.

\section{Accessibility}




\section{Dualistic Forms}

\section{ALEXANDER REHDING}

The trio of nineteenth-century harmonic dualists, Moritz Hauptmann, Arthur von Oettingen and Hugo Riemann, is not generally thought to have contributed much in the way of a theory of musical forms. ${ }^{1}$ Their major objective was to overhaul music-theoretical speculation at the chordal level, proposing, each in their own way, that the minor triad should be conceptualized as the polar opposite of the major triad, with the "root" at the fifth. ${ }^{2}$ Over this ambitious project, which amounted to no less than to a reconceptualization of one of the cornerstones of musical thought, they were mainly concerned with harmony on the chord-to-chord level, and rarely considered large-scale structures as a whole. $^{3}$

To complicate matters further, the only dualist prolific enough to consider matters of form in his writings, Hugo Riemann, seemed to insist on the strict temporality of musical form, which is difficult to square with the essentially spatial conception of harmony that invariably underlies dualistic ideas. Witness his contrast between music and architecture, as explained in his Systematische Modulationslehre (1887): 
It is possible, and to a certain extent self-evident, that an architectonic work of art is initially captured in its totality by a single gaze and only then analytically dissected into its details. An understanding of musical art, by contrast, can only be gained by pursuing the opposite strategy; for even a printed score lying in front of us cannot first be understood as a whole and then in its details, because the reader (who is, after all, hearing in his imagination) must build up the musical work from small fragments lined up one after the other. These fragments are presented in temporal succession and are combined by the listener's memory into larger components. This understanding of the whole is the consequence of a progressive synthesis. ${ }^{4}$

Riemann could fall back on the entrenched association between architecture and "frozen music" that had pervaded romantic thought since Schelling and Schopenhauer. Unlike those earlier thinkers, however, Riemann used the comparison to different ends. As he never tired of emphasizing, the act of listening should be thought of not as passive enjoyment but as a logical activity, where the listener had to build up the form of the piece in his mind gradually. This logical activity meant for Riemann in particular that the listener should hear music in full units of metric periods and complete harmonic progressions. ${ }^{5}$ 
These very basic points are, unfortunately for subsequent music theorists, the only ones that remain more or less constant in Riemann's intellectual career. Pressured by dire financial needs, Riemann was a Vielschreiber, and the first victim of his necessity to keep publishing was theoretical consistency. ${ }^{6}$ While it is undeniable that Riemann worked toward one grand project, his views on form appear for the most part scattered, and sometimes only partially thought out. Across his theoretical writings, no less than four distinctive approaches to form can be identified, which focus on periodic, thematic, harmonic and sectional constructions respectively.

From his analytical essays, particularly his rather segmentalized analyses of Beethoven's sonatas, it seems that he understood meter, expressed in ideal types of eight-measure periods, to be the primary bearer of musical form. These periods, to be sure, are largely predicated upon harmonic rhythm, as William Caplin explores further in his contribution to this volume, but it rarely occurred to Riemann to consider the harmonic relations between these large-scale units. ${ }^{7}$ Rather, as Scott Burnham has noted a propos of Riemann's analytical practice, form was for him an open-ended process of eight-measure periods strung together one after the other. ${ }^{8}$ This would constitute another difference to architecture, or rather the flipside of Riemann's above comparison: while the totality in an architectonic work of art is 
clearly demarcated, there was nothing in Riemann's system to limit the series of periods of which musical form was constituted. In this approach the musical totality must remain mysterious.

Considering this problem in his theoretical model, it seems surprising that Riemann would also consider musical forms in the traditional Formenlehre approach at the same time, using letter designations of the type A-B-A, without noticing a discrepancy. ${ }^{9}$ Given Riemann's preoccupation with eight-measure phrases, it is not clear how these standard forms should square with the concatenation of periods. There is little to suggest, beyond common sense, according to what criteria the larger sections should be demarcated, as opposed to eightmeasure units within each of these sections. Put differently, Riemann's basic idea of musical form seems to follow two different guidelines: up to the eight-measure level, there is a continuous hierarchy with units building up bottom-to-top from smaller entities, while beyond that, his Formenlehre labels would only seem to make sense when understood as derived top-to-bottom and would therefore seem to be "architectural" rather than "musical." Between these two notions of musical form there is a gap that appears unbridgeable from within his theoretical system.

This need not have been this way. For in principle Riemann was quite willing to acknowledge that form is also articulated through harmony. 
In his monumental Große Kompositionslehre he made an effort to put his Tonnetz to analytical use when he showed that the development section of the first movement Beethoven's Bb major Quartet op. 18, no. 6, touched on "the keys of $\mathrm{G}$ minor, $\mathrm{F}$ major, Eb major, Db major, and F major." Riemann was not interested in the scalar implications of this sequential progression, which in a non-dualistic space could be seen to outline part of a descending whole-tone scale, before returning to the key of the dominant. Instead, he considered the arrangement of these keys "in their very close proximity to Bb major," the center of tonal relations of this movement. Example 1 shows how these keys relate to each other and to the central harmony of $\mathrm{Bb}$-major along the lines of Riemann's Tonnetz.

This (admittedly rudimentary) analysis presented in Große Kompositionslehre brings the structural role of harmonies into the discussion, but it still results in a fairly amorphous musical form. It seems here that Riemann imagined form to be constituted, somewhat eclectically, from the interaction between harmonic moves across the Tonnetz and large-scale A-B-A formal models. These two approaches to form are juxtaposed in Große Kompositionslehre, but their interaction is not further clarified. 
Riemann came closest to tackling the problem of form in Katechismus der Kompositionslehre of 1889, his only treatise dedicated entirely to the theory of forms. He wrote:

So far, [modulation] was only introduced as a means of filling in the metric scheme, but not as a means of creating form beyond a closed [metric] scheme. But now we shall proceed to a totally different approach, by structuring the order of large-scale forms according to their contents. We no longer regard the metric scheme as any more than a means of creating form on the small scale. ${ }^{10}$

This decision to base form on harmony in this way resulted in quite radical consequences. (And it is probably no coincidence that it was during the same time that Riemann thought most intensely about his notion of harmonic function, which he published only a couple of years later. ${ }^{11}$ ) In this treatise Riemann proceeded to introduce musical forms as four abstract types, irrespective of genre, texture or function, and actively discouraged his readers from using the conventional generic names, such as rondo or sonata forms. ${ }^{12}$ All forms were, for Riemann, reducible to the basic pattern of A-B-A (which for him signified "main idea—subsidiary idea—main idea," or Hauptgedanke—NebengedankeHauptgedanke) in various degrees of elaboration. ${ }^{13}$ 
When viewed from this angle, musical forms for Riemann were apparently not so much about distinct formal schemes or types, as rather about an abstract notion of formal process. As he explained in his Musiklexikon, the basis of all musical form was for him the restoration of an original unity at higher level, by means of the resolution of a contrast or conflict:

No art can do away with form, which is nothing but the combination of the parts of the artwork into a whole. Such a combination is only possible if the diverse elements are in a deep inner relation to one another. If not, the result is merely an external unity, a succession. The supreme demand for all form, including musical form, is unity. Its aesthetic effect can only fully unfold in the context of opposition, as contrast and contradiction (conflict). ${ }^{14}$

This organicist approach to form, which owes much to Hauptmann's musical dialectics, allowed Riemann to move beyond the problems that beset his diverse approaches to musical form. When discussing fugues, for instance, Riemann suggested that there was no essential difference to the other forms: tonal order in fugues could be described in the same way as any other formal types. Because the fugue is, as a rule, a monothematic form, it can even serve to show more clearly the 
underlying processes that produce contrast and resolution. What ultimately mattered, Riemann maintained, were not themes, but the harmonic plan: "In other words, such richly elaborated musical works with only one theme (whatever the rhythmic and melodic features, without thematic contrast) reduce the structuring of form to the harmonic element." 15

Riemann was suspiciously silent as to what this "harmonic element" actually entailed. Of course, harmony was for Riemann inextricably bound up with the idea of dualism. And this is, one assumes, also the reason that Riemann was reluctant to put his radical theory of forms into analytical practice, or rather why the more fragmentary approach to form postulated in the later Große Kompositionslehre may seem like a step back. The controversial theory of harmonic dualism, in its pure form, had rather little to do with the harmonic order as it could be found in most musical works.

An obvious problem to harmonic dualism are, for instance, multimovement works, such as Beethoven's Symphony no. 5, which begins in a minor key and ends in the parallel major key: "Such transport from minor to major ('through darkness into the light') is of decidedly gripping effect and certainly justified, although the unity of key is affected by it." ${ }^{16}$ The reason Riemann was so disturbed by an ordinary modal mixture is that for harmonic dualism the reference tone switches 
between major and minor (in Beethoven's Symphony no. 5 , from ${ }^{\circ} \mathrm{g}$ to $\mathrm{C}^{+}$, to use Riemann's standard dualist shorthand ${ }^{17}$ ), which would beg the question of synthesis, of the higher unity that Riemann posited for all musical forms. And who would be prepared, save for Riemann, to argue that Beethoven's Fifth Symphony was lacking in unity?

It seems that this dualistic notion of resolution and synthesis, so central to Riemann's understanding of form, would have to be realized in a different way from conventional notions of form. In other words, the mismatch in Riemann's theory of forms-between the abstract notion of synthesis he described in his theories on the one hand, and the concatenation of periods that marked his analyses on the otherwas dictated by the constraints of applying his very particular principles of harmony to a given repertoire of music which did not fully represent his idea of how music ought to work. ${ }^{18}$

It therefore seems that if we want to explore the notion of dualistic forms we need to orient ourselves by his theoretical writings more so than his published analyses. ${ }^{19}$ The first movement of Brahms' late Clarinet Trio op. 114, written in 1890-91, might serve as a test case of what such a theory might have looked like. While this choice is, to a certain extent, determined by what can be shown analytically in it, it is not arbitrary. Over the course of Riemann's life, Brahms assumed an ever-larger role in the musical pantheon that Riemann promoted in his 
theoretical and historical works. In this spirit, Katechismus der Kompositionslehre, Riemann's most concentrated treatise on form, was dedicated to "the master Johannes Brahms."20

An analysis of this kind, within a theoretical framework that was never fully established in its own time, is necessarily a hypothetical and highly speculative enterprise. The endeavor has a distinct historical tinge to it-it invites us to listen to a piece of music with period ears, as it were, to use analytical tools that are, more often than not, in our day confined to the dustbin of history. ${ }^{21}$ At the same time, it would be overstating the claims such an analysis can make if we tried to argue for any historical fidelity in this endeavor: we already know that Riemann, or his contemporaries, did not analyze music in this way.

This theory of dualistic forms is best understood as the reconstruction of a theory that never was, but could have been. It is perhaps best described as an attempt to take Riemann's theoretical claims seriously, more seriously than he did himself, and to try and put them into analytical practice. For this we need not suspend our experience of music and analysis. Rather, such a reconstruction should serve to enrich our appreciation of the musical work, as do most analytical efforts in our time (or so one hopes). The ultimate goal is therefore not an exercise in antiquarian history, but rather in utopian 
thinking: it aims to show how these "vintage" tools can lead to different, and often startling, concepts of form.

But, as always, there is a second side to this analytical project: any potential analytical success also vindicates the premises of the theory. And so, if it becomes possible to assert a "dualistic form," this raises the question of what this tells us about the work of music under scrutiny. One striking feature of most dualistic theorizing in the nineteenth century was that it had comparatively few musical examples to draw on. ${ }^{22}$ The pure dualistic approach has, consequently, been reproached for its insensitivity to musical concerns. What would it mean to find a piece whose form can be shown to follow dualistic principles? Could this counter the reproaches against dualism's dubious relation to actual musical works? Could this, indeed, form the starting point of a genuinely dualistic repertory?

A word of caution seems in order here. Carrying out an endeavor of this nature is a tightrope walk of theoretical mediation. On the one hand, it is important to remember that the dialogue between theory and practice is more complicated than meets the ear: even where composers and theorists emerged from the same cultural context, as is the case here, we cannot simply assume a one-on-one mapping of compositional and theoretical structures. On the other hand, in this exercise in utopian thinking it is important not feel overly constrained 
by the desert of reality. ${ }^{23}$ What matters is to examine carefully the mutual relationship between the repertory under analytical scrutiny and the theory that is brought to bear upon the music. Any theory of dualistic forms will have to be located in this forcefield between speculative principles and compositional practice.

I

Let us ignore Riemann's aesthetic difference between architectural and musical forms for the moment and treat Brahms's Clarinet Trio in A minor as though it were a work of architecture. Let us briefly survey the formal outline, viewed in the score as a totality. If we take a stroll around the first movement, which in the critical literature is often given short shrift beside the more famous Clarinet Quintet, ${ }^{24}$ the outer form seems by and large unremarkable..$^{25}$ The exposition touches, in typical Brahmsian fashion, on three key areas, moving from A minor to $\mathrm{C}$ major, followed by a closing section in $\mathrm{E}$ minor. The development includes, surprisingly, an intermittent key change to F\# minor and leads back to A minor. The recapitulation is consequently blurred: the home key is already reached at the beginning, and the first subject is not restated. The second-subject material is restated in the diatonic lowerthird relation $\mathrm{F}$ major, as if to balance the third-relation of the exposition. At the same time, the lower third allows an easy return to 
the home key: where the exposition closed a major third up from $\mathrm{C}$ major to $\mathrm{E}$ minor, the same interval in the recapitulation leads back from $\mathrm{F}$ major to $\mathrm{A}$ minor. A coda concludes the movement.

We could do worse than to enter the inside of the movement at the main portal, or the first subject, which opens the work, to marvel at the details and hear the work unfold temporally before us in the manner Riemann suggests in his aesthetics. The opening subject appears to be a rather clear-cut, if slightly bald, twelve-measure unit, shown in Example 2. The first four measures, played by the cello alone, sustain an A minor harmony, arpeggiating upwards and elaborating it downwards to comprise the entire natural minor scale. ${ }^{26}$ The fourmeasure phrase is metrically guileless, and articulates an iambic pattern, which is numbered 1-4 in the example, in Riemannian fashion. ${ }^{27}$ Clarinet and piano enter at measure 4 , repeating and varying the opening phrase, but extending it to full eight measures. ${ }^{28}$ (The figure (2) before measure 6 indicates, in Riemannian fashion, that the previous measure should be understood as a restart of the metrical unit.) The clarinet part brings in some harmonic movement, as it shifts from the tonic to the minor subdominant (with its "underseventh," 29 i.e. its sixth scale degree, B), closing on what Riemann would call the tonic "variant" (and which in other harmonic systems usually goes by the English name of "parallel.") 
While the subdominant is often considered by "monists," such as Helmholtz, not to imply a genuine harmonic shift, ${ }^{30}$ this is not so for the dualists: since the Clarinet Trio is in a minor key, the subdominant does constitute a significant function-as shown in Example 3, it is the precise inversion of the dominant seventh in the major key. For a dualist it may also not be coincidental that at the tutti moment at measure 4 all three instruments come in on $E$ in the respective octaves, as $E$ is the dualistic primary note of $A$ minor $\left({ }^{\circ} \mathrm{e}\right) .{ }^{31}$ It is only from this primary note that the bass line in the piano descends from $\mathrm{E}$ to $C$ and then settles on a pedal $A$, outlining the components of the $A$ minor chord in its dualistic order.

This last observation might seem basic, trivial even, but in fact the directionality of chordal dualism has always been a bone of contention. Yet some valuable insights can still be gained from it. David Lewin has reinforced some aspects of dualistic listening strategies, shifting the emphasis slightly from Riemann's root-like "primary" tone to the notion of a "pivotal" tone of a triad which need not be its root. ${ }^{32}$ Using short examples from the openings of Brahms's Intermezzo op. 119 no. 1, and The Rite of Spring, he demonstrates how the fifth of a triadic sonority can be the pivotal pitch. Although Lewin, unlike the dualists, does not distinguish between major and minor sonorities in this casehe uses the opening of the Alla danza tedesca from Beethoven's string 
quartet op. 130 as an example of a major triad that "works downwards" from its fifth-it seems that this listening strategy can be successfully applied as a starting point for this piece. In fact, the largescale harmonic areas of the exposition in Brahms' op. 114 can be seen as revolving around the pitch $\mathrm{E}$.

There are three harmonic areas in the exposition: $\mathrm{A}$ minor, $\mathrm{C}$ major and $\mathrm{E}$ minor. The feature of a "double" harmonic move from the principal key area is not unusual in Brahms's sonata forms, and is by and large, as James Webster has pointed out, derived from his study of Schubert's sonata forms. ${ }^{33}$ This exposition, however, is somewhat unusual in that it tonicizes harmonic areas a third apart. Precedents with the same harmonic outline can be found in only few works that we can expect Brahms to have known: among them Schubert's D minor quartet (d-F-a), and Beethoven's Coriolanus Overture (c-Eb-g), but the way in which synthesis is achieved in the recapitulation in any of these works, is rather different from Brahms's Clarinet Trio. Within Brahms's oeuvre, too, this is the only first movement in a minor key to employ this harmonic procedure. The second symphony may be cited as a reasonably close example in a major key, where the exposition moves from $\mathrm{D}$ major to $\mathrm{F \#}$ major and to A major. But the major key sets very different standards: by moving on from the secondary key area, the dominant is reached in the second move, and the conventional polarity 
of tonic and dominant is reinstated. The same, however, cannot be assumed in a minor context; there it would seem-at least in the abstract-that the closing subject in the minor dominant shoots over the goal and may be regarded as formally redundant.

As Example 4 shows, each of the tonicized triads of the exposition is grouped around E, which in this way appears "prolonged" throughout the exposition. In accordance with Riemann's principle of triad representation or Klangvertretung, the $\mathrm{E}$ itself is heard in a different context and changes its significance accordingly from "principal tone" to third to "lower fifth." ${ }^{44}$ What is happening here can be represented well by means of Moritz Hauptmann's chain of thirds, as in Example 5, his distribution of the diatonic scale in intervallic and ultimately chordal units.

Tonic value-in Riemann's specific sense as explored by Brian Hyer's contribution in this volume-is transferred between the first and second subjects from the A minor triad to the $\mathrm{C}$ major triad. In this case, it is done very subtly, as the thematic substance of the second subject is closely oriented towards the first subject. As can be seen in the lower stave of Example 6, the second subject tonicizes $C$ major, but there is a palpable element of the home key A minor present. In fact, the opening of the subject descends from $E$ along the $A$ minor triad before it replaces the "under-fifth" A emphatically for its diatonic 
neighbor G. Furthermore, the canon per inversionem between measures 52 and 63, included in Example 7 below, is based entirely on the oscillatory power of the subject between $A$ minor and $C$ major, which is not resolved throughout the passage. (It is in this feature especially that the Clarinet Trio reveals itself as the sister piece of Brahms's op. 115 with its harmonically ambivalent opening.) On closer inspection it appears that the tendency towards $\mathrm{C}$ major is already dormant in the first subject: as the upper stave of Example 6 indicates, there is one occasion where a pitch other than a component of the A minor triad occurs in a metrically strong position, $G$ at the downbeat of measure 2. ${ }^{35}$ In the melodic shape of both subjects a triad note is literally replaced for its diatonic neighbor: in the first subject $G$ for $A$, and in the second subject, more obviously, A for G. The harmonic areas of the first and the second subjects therefore describe little more than a shift of emphasis on what can be seen as the basic structure common to both.

There seems to be altogether very little contrast between the first and second subjects. The harmonic similarity is further underlined motivically by the close relation between both themes, as Example 6 above showed. It seems entirely appropriate to express this close relation, as is shown in Example 8, by attaching Riemann's label $T p$, or Tonikaparallele, to this key area. ${ }^{36}$ 
A more decisive harmonic shift occurs only with the move to the minor dominant at measure 63 , reinforced at measure 67 , where new thematic material is introduced. Here, for the first time, a reference to the home key of A minor is finally abandoned. Instead, E minor, its minor dominant, is sounded. On closer inspection, however, a similar subtle link of the two key areas becomes noticeable in the melodic detail of the material: as Example 7 shows, the second subject soon exchanges the $C$ for its semitonal neighbor $B$ at measure 47 . The piano accompaniment, only sounding $G$ and $E$, supports this harmonic ambiguity between $\mathrm{C}$ major and $\mathrm{E}$ minor: is $\mathrm{B}$ a long passing note between $\mathrm{C}$ and $\mathrm{G}$, or is $\mathrm{C}$ a suspension to $\mathrm{B}$ ? Similarly, two measures later, the upper neighbors of the dominant seventh chord to $C$ major themselves outline an E minor chord; the sparse piano texture only confirms the dominant seventh a measure later. With a view to the $\mathrm{E}$ minor closing theme, the second subject functions as its leading-note change, and should be heard as $\boldsymbol{B}$ or Dominantleittonwechsel. ${ }^{37}$ The total harmonic work of the exposition can be summarized in Riemann's terms of function as shown in Example 9: the functional representation shows how the second-subject area relates to its surrounding context, functioning both as $T p$ and retrospectively as $B$. 
While Riemann's taxonomy assumes the tonic a priori, ${ }^{38}$ Hauptmann's dialectical approach problematizes it. In Hauptmann's dialectical notion of harmony the closing theme of the sonata has left its state of initial unity, and has "come into opposition or contradiction with itself." 39 The progressive transference of tonic value, from $\mathrm{A}$ minor to $\mathrm{C}$ major and $\mathrm{E}$ minor, that we have observed in the exposition makes this dialectic very graphic: is $A$ minor the subdominant of $E$ minor, or is conversely $E$ minor the dominant of A minor? Or, in Hauptmann's terms, does A minor have a dominant, or is it a dominant-in this case the lower dominant-of the potential tonic E minor? Hauptmann expressed his dialectical idea of tonality by means of a "triad of triads," as shown in Example 10 (in Hauptmann's C major), where tonality is established in three stages.

What Hauptmann described in the "triad of triads" is essentially the logical process from an unmediated major triad to its dialectically asserted position as the centre of a tonality. ${ }^{40}$ (Hauptmann only describes the "triad of triads" for the major system, but his stringent symmetrical bias makes it inevitable that an equivalent scheme is valid for the minor system too.) After stating the triad (at I), another fifthrelated triad is sounded to challenge the first in its central significance. Since the position between two fifth-related triads is always ambiguous, as we just saw at the end of the exposition in the Clarinet 
Trio, it is impossible to decide whether the relation should be heard as a tonic-dominant or subdominant-tonic. It has come into opposition with itself, which is what is described in the two alternative versions of (II). It is only when the other fifth-related chord is introduced that the first chord can be reinstated as a central triad-now as confirmed tonic. The synthetic task of the tonic, as (III), consists in simultaneously "being" dominant (to its subdominant) and "having" a dominant itself. ${ }^{41}$

This ambiguity of function at the end of the exposition, stage (II) in Hauptmann's "triad of triads," is encapsulated in the cadence that concludes the exposition in measure 82, shown at the end of Example 11 below. Unusually enough (but perfectly explicable in the context of this movement), the cadence is plagal. Here the plagal cadence serves as a fleeting reminder to the home key $\mathrm{A}$ minor, which makes an appearance there not in its central meaning as the tonic, but merely as the subdominant of its dominant, and underlines in this way the dialectical stage of opposition into which the movement has entered.

III

The development section of the opening movement of the Clarinet Trio is distinctly un-Brahmsian. While it has become something of a cliché to say of a Brahms sonata that the development spans the entire piece, 
beginning at the first measure and ending with the last, the opposite seems to be true here. Where traditionally the development, and particularly the Brahmsian type, is the section that generates most harmonic (and motivic) interest, this development section is so plain that it is doubtful whether it is appropriate to call this a development section at all. It seems in many ways as though the development section "undoes" the exposition. For what it does is mainly to restart the exposition in the dominant key: it abridges the first 33 measures of the movement by simply sounding the first subject, simulates the climax of measures $22 \mathrm{ff}$, and cadences on $\mathrm{C \#}$ at measure 96 . When the home key of A minor returns at measure 125 , leading into the recapitulation, we seem to have gone full circle: the bass line of the exposition arpeggiated the A minor triad upwards (in other words in inverted direction, towards its dualistic son générateur, the fifth), while the development section describes the A major triad downwards, also against its imagined direction.

The development section is chiefly concerned with establishing this C\#. Although the key signature of the exposition suggests F\# minor, the only cadence in this key is on C\# major at measure 96. The urge towards a chromatic $\mathrm{C \#}$ is first noticeable at the end of the exposition. As Example 11 shows, the clarinet takes up the closing theme again but alters it chromatically-from $\mathrm{C}$ to $\mathrm{C \# -to} \mathrm{land} \mathrm{on} \mathrm{the} \mathrm{wrong} \mathrm{note}$ 
at measure $74, A \#$ assisted by the piano's C\#, which would resolve into B minor. The phrase cannot be closed, as a consequence of, as it were, the wrong harmonic turn it has taken. Instead, the wrong measure is repeated obsessively, as if a gramophone needle skipped over a scratch in the record and played a snippet of music over and over again. ${ }^{42}$ Riemann's metric enumeration, which cannot continue until the next heavy beat occurs, makes this repetitiveness particularly clear. In this way, the theme, which in its original guise only comprised five measures, is extended to a long twelve-measure period. (Note that the final measure is assigned the metric value "9" indicating a relatively lighter beat, as tonic resolution is absent from the measure.) The piano accompaniment underscores these "needle skips" by a change of texture, which replaces the arpeggiated figures in the left hand for octave jumps. Only in measure 77 , when the clarinet finally "corrects" itself and reinstates the original $A$ natural and the piano its $C$ natural, can the phrase come to an end in E minor. The exposition is evidently too early as a locus for chromatic alterations.

Within the development section, the $\mathrm{C \#}$ also has a decisive influence on the harmonic events. The descending circle of fifths starting at measure 105-for Riemann a procedure that is excluded from tonality ${ }^{43}$-is interrupted at measure 110 : C\#, which had already been surrendered in passing, in the dominant seventh chord on $D$ in the 
previous measure, is taken up again, thus disturbing the chain of seventh chords. The significance of the G major triad is changed with the addition of the $\mathrm{C \#}$ passing note to sound like a subdominant to an unsounded D major triad. The confused harmonic progression is thus short-circuited, as Example 12 shows, and, after briefly returning to $E$ minor at measure 114, further anticipates $D$ major by means of a dominant pedal on $A$ between measures 115 and 117 . In analogy to the suppressed C\# above, it seems that the development section is too early for D major, which merely gives the listener a hint for things to come.

\section{IV}

As often in Brahms's chamber music, the beginning of the recapitulation is blurred: the return of the first subject is completely suppressed, while a return to the home key of A minor can be registered at measure 125 . The second subject is restated in F major, a perfect fifth below its first occurrence. This procedure is not uncommon-perhaps the most famous example of a recapitulation in the submediant is found in Beethoven's Waldstein sonata. But as we noted a propos of the exposition, the minor tonality of the movement makes all the difference: in the Waldstein sonata, the recapitulation in A major balances the second subject's occurrence in E major in the 
exposition. ${ }^{44}$ In this way this harmonic scheme of the sonata substitutes for the conventional fifth relation between the initial and final occurrences of the second-subject area. Riemann's taxonomy of harmonic function, and its notion of apparent consonances (Scheinkonsonanzen), is particularly good at expressing such relations, as shown in Example 13. The upper and the lower third-relation, expressed through the "relative" (Parallele) and "leading-tone change" (Leittonwechsel) respectively, demonstrate the relation to the tonic, while encompassing between $T p$ and $\mp$ the fifth that separates these two occurrences. One immediate advantage of such a procedure in this piece is of course the convenient recapitulation of the closing theme: no retransition is necessary; the transposition a fifth down means that the closing theme is automatically restated in the home key.

The main point of this harmonic scheme, however, does not seem to be an expedient means of achieving closure: the movement does not actually end with the restatement of the closing theme, although all the "work" of the sonata form has already been accomplished at that stage. ${ }^{45}$ What happens instead is that the closing theme is repeated in a changed version in A major. The new version of the closing theme fulfils what the development presaged through its C\#. The altered theme, reproduced here in Example 14, is achieved by reinterpreting the $\mathrm{F}$ enharmonically into $\mathrm{E \#}$ as an accented chromatic passing note to 
F\#. This very slight change opens the melodic range immensely, and gives the whole passage a radiant, utopian shimmer. Although most accounts of the form of the movement would end here, the piece is not at an end-the dualistic dialectic of the sonata is still incomplete.

We should remember that the opposition at the base of the dualistic dialectic of this movement does not reside in the conventional opposition between first and second subjects-or indeed, the pertinent harmonic areas-but rather in the articulation of a structural symmetry in Hauptmann's sense. Hauptmann holds that the stage of "opposition," of the tonic "splitting up within itself," must be reconciled by reinstating it in its unambiguous central position, by showing that the tonic both is and has a dominant. The tonic, in other words, must be shown from all sides: as a "dominant" in relation to its subdominant, and likewise, as the "subdominant" of its dominant. Or, along the chain of thirds, the move to the dominant side achieved in the exposition must be balanced by an equivalent move in the other direction, to complete the harmonic scheme, as shown in Example 15.

The missing move to the subdominant has indeed been prefigured in the harmonic insinuations towards D major in the development section. The articulation of this key follows in the cadence at measure 194 and is prepared in measure 190, directly after the A-major theme of Example 14 above, which I described as "utopian." This attribute is 
meant here in more than a descriptive sense, for neither is A major the tonic of the movement, nor D major its subdominant. Indeed, the dualists were agreed that the minor mode cannot have a major subdominant. ${ }^{46}$ Rather, the $\mathrm{D}$ major cadence must be seen as the tonicization of the subdominant required in Hauptmann's scheme: the "utopian" home key of A major functions as the dominant to D major; D major has a dominant.

Numerous allusions to the kind of symmetry that Riemann's aesthetic requires between the most minute detail and the large-scale structures pervade the surface of the piece. Witness the passage in the exposition in Example 16, which melodically mirrors the eighth-note figures at measure 15 and 17 respectively, and harmonically emphasises the "upper" and "lower" sonorities of the pedal E in the clarinet and cello parts. Similarly, at the same point in the recapitulation, in Example 17, the functional opposition is brought out by first outlining a move from $A$ up to $D$ (as tonic to subdominant), which is then paralleled by a move from $A$ down to $E$ (representing, if not actually sounding, the tonic and its dominant).

The need for a subdominant to balance the harmonic skeleton of the movement has long been foreshadowed since the exposition. The errant cadences at measures 18 and 20, reproduced in Example 18, both point towards the subdominant region. At that early point in the 
piece, they seem somewhat unmotivated and appear to function merely as a suspending device to prepare for the outburst in the following measures. However, their effect is carefully calculated: the second cadence especially is difficult to pin down-are they really plagal cadences (in A minor), or perhaps imperfect cadences (in D minor)?

Part of the unsettling effect of these two short moments is set up by means of metric instability. After the presentation of the first subject until measure 12 , the pedal $E$ hovers for five quarter-notes before the piano enters with a connecting motive. This is a long enough time to unsettle a sense of metric order (especially given the half-note beat), and it is aggravated by the contradictory onset of the motive, which clearly demands a downbeat beginning, at an upbeat moment so that the listener is inevitable a quarter-note "out." 47 Although a sense of down and up quarter-notes is partly restored by the end of each phrase, it is no longer possible to hear whether the chords of measure 18 are on the first or second half-note of the measure, in other words, whether the F major triad possessed greater metrical weight than the A minor triad or vice versa.

Also in the following phrase-where the metrical instability is catapulted into three-measure phrases and triplet rhythms on various levels-the subdominant plays a crucial role. Most pertinent is the 
strange interrupted cadence at measure 27 , as shown in the second half of Example 18, where the triads $\mathrm{D}$ major (which is nothing but Riemann's “impossible” major-subdominant-in-the-minor-mode) and E major resolve into $D$ minor. The function of this interrupted cadence is best understood as a minor tonic Leittonwechsel Parallel (T/ ); this is in fact the farthest extent to which Riemann was prepared to take his theory of harmonic function. ${ }^{48}$ The function label describes that in this metric-harmonic position a tonic function is expected, but the sounding chord only has one pitch in common with the tonic chord. We have moved there by modifying it with two apparent consonances (both Leittonwechsel and Parallel apply successively). It also shows clearly how the harmonic space of the dualists is shaped distinctly differently from Roman numeral space, which would simply declare this chord to be $I V .{ }^{49}$ This strange moment, of the $\mathrm{D}$ minor chord sounding without functioning as subdominant, is indeed closely paralleled by the "impossible" D major passage that we encountered in the recapitulation, and its lacking fulfillment of the subdominant function.

Back in the recapitulation, it is only when the harmony of the $D$ major passage finally changes to a more "real" (and functional) D minor in measure 208 that its subdominant significance is fully articulated: Example 19 shows how in the following measures, which introduce the 
coda, the D minor harmony even receives its "characteristic dissonance" that identifies it unambiguously as a subdominant.

In this sense, we can hear the recapitulation, in analogy to the exposition, as depicted in Example 20. Symmetry and dialectical synthesis are finally achieved. Example 20 juxtaposes the difference between a conventional, "monistic" and a dualistic hearing of the piece: the conventional version would pay more attention to the "synthesis" of the diverse key-areas, that is the first and the closing themes returning in A minor/major, as expressed by the upper beam in the graph, whereas for the dualists the downward move from A minor to $D$ minor, expressed in the lower beams, would represent the actual synthesis of the movement.

The D minor moment at the coda, which is of no particular interest in a conventional reading, is the moment of dualistic epiphany where everything falls into place. Is it just by accident that the subjugation of the $\mathrm{D}$ major into functional tonality coincides with a quotation in the piano from the first of Brahms's Four Serious Songs op. 121, Denn es gehet dem Menschen wie dem Vieh, written shortly after the Clarinet Trio? The underlying sentiment of resignation of this song, reproduced here in Example 21, contemplating human transitoriness and death-a dystopia if ever there was one-is in every way the negation of the utopian quality conjured up just previously. 
It is one of the most fascinating aspects of this movement that the quotation from Denn es gehet dem Menschen wie dem Vieh had been used as a connecting motive throughout the movement; it is the very motive that created metrical disorder from measure 13 onwards. In spite of its prominence, it does not stand out as the quotation that it is until this very late moment. In all its prior occurrences the quotation had been disguised in one way or another-through figuration in triplets (measure 13, shown in the piano accompaniment of Example 16 above), subdivision into breathless two-note motives (measure 35 ), appearance in various harmonisations, or transformation into the major mode (measure 115).

After the allusion to the Serious Songs, the utopian A major triad has lost its transfigured shimmer; its aura has become hollow. As a variant in the major mode, it lacks the affirmative power of a real tonic. In spite of the repeated plagal cadences between D minor and A major, the movement does not attain full closure-at least not in a tonal universe where major and minor follow different paths. The expected A minor resolution is only granted at the end of the final movement, and there, in like spirit, it is also preceded by a quotation in the piano from one of the Serious Songs: $O$ Tod, wie bitter bist $d u$. 
Returning to Riemann's initial conceit regarding the contemplation of an architectural and a musical work of art, we finally know the structures of its detail to project them onto the large-scale form. The very first phrase now reveals itself-in true organicist fashion-as a microcosm of the entire piece: its harmonic skeleton in Example 22 prefigures the shift from A minor $\left({ }^{\circ} T\right)$ to its "utopian" variant A major $\left(T^{+}\right)$with its strong plagal element and has very pronounced repercussions with the structurally important points at the end of the exposition and the coda in its entirety.

And so we can reassemble the entire work in dualistic fashion. The exposition explored the "right" side of the tonic, with its dominant harmonies, while the recapitulation (and the coda) complemented this with the "left", subdominant harmonies. Only after this full exploration of the tonic, when, following Hauptmann, it has been re-affirmed as the "central" sonority in this literal, dualistic sense, can tonality be understood to be established unequivocally. In such dualistic terms, the entire movement can therefore be heard to be laboring towards this end. Genuine dualistic synthesis is not reached until the final phrase, with the end of the coda-and only if we hear it with dualistic ears.

But what does it mean, putting it somewhat fancifully, to "hear with dualistic ears"? In phrasing it this way, a strong claim is impliedparticularly considering that the first and most powerful criticism of 
the dualists had always been that we do not hear music in this way. ${ }^{50}$ What we have been doing here is to assume, contrariwise, that the dualists take their fundamental theoretical position seriously-more so, perhaps, than they themselves dared to do at the time-and to draw out the final consequences of this understanding of harmony in its application to musical form. The theoretical moves in this analysis are all founded on the principles of Riemann and his colleagues posited.

It turns out that the dualistic view of form in the case of Brahms' Clarinet Trio opens up a model of synthesis that is otherwise inaccessible. But does the Clarinet Trio need dualistic theory (to readjust its position in the chamber-music canon) more than the theory needs the piece (to valorize its claims)? It need not be pointed out that it would be absurd to claim any form of intentionality in this case. We can be almost certain that the Clarinet Trio was not composed with dualistic theorizing in mind. But it might be possible to triangulate theory and repertory in a somewhat more abstract way. ${ }^{51}$

If we take a step back from theory and repertory, we can see that the same fascination with oppositional symmetry that underlies the basic idea of harmonic dualism also seems to be at play in Brahms' sonata movement. ${ }^{52}$ From perspective of oppositional symmetries, a number of other musical works of that period, for instance by Wagner and Liszt and their experiments with symmetrical divisions of the scale, 
can also be considered under this dualistic angle. Perhaps the conjunction between dualism and harmonically derived musical forms is best viewed, ultimately, not so much as a formal model that yields concrete analytical insights-it would probably yield slim pickings if strictly formalized in this way, as explored here in the lonesome example of Brahms' Clarinet Trio.

Rather, it would seem most fruitful to consider the utopian project of "dualistic forms" as a reflection of a music-historical mode of thought in the late nineteenth century that affected theory and composition alike. It seems, almost paradoxically, that the more we squint while gazing at the musical work of art, in the way Riemann suggested, the more clearly the dualistic theory of form comes into focus.

\section{VI}

Before we close our eyes and fully succumb to the utopian fantasy of a dualistic theory of forms, however, it might be worth recalling the reality with which we started. Or, put differently, remember how we said earlier that no matter how closely related repertoire and theory may appear, they always need to be triangulated and mediated via the position from which we mediate between theory and musical work. As Cristle Collins Judd puts it in explicitly geometrical terms, "If we 
imagined a simple two-dimensional representation of a triangle, our vantage point at the top of that triangle would connect us to both the theory and the practice, while reminding us that the triangle is not closed: the mediation between the two is our activity." ${ }^{53}$ In this case, the task of triangulation was considerable. We started with the observation that the nineteenth-century dualists were lacking an explicit theory of form, and we hypothetically constructed one for them, with distinctly injects the interests of early-twenty-first-century Anglo-American music theory into this nineteenth-century enterprise. It is clear from Riemann's writings that he was gesturing toward such a theory, and there is nothing to suggest that this analysis would not have met with his approval, but no matter how hard we squint, this dualistic theory still remains a hypothetical reconstruction or, as we called it earlier, an exercise in utopian thinking.

It is now time to disentangle ourselves from this complicated constellation, and to consider the implications of the lack of such a fully-fledged theory of form. What does it mean, in other words, for a group of theorists to be formalists without a theory of form? In fact, for the longest time this odd status was a thorn in the dualists' side, as they felt vulnerable to attacks in this regard, particularly from the Schenkerian camp. Witness Hellmut Federhofer, for instance, who argued that Riemann lacked a cohesive concept of large-scale

Prof. Alexander Rehding 6/6/07 9:29 AM Comment: She also warns, "The chronological proximity of a theoretical source and a musical repertory guarantees no easy, obvious, or even necessary relationship." P. 6 
structure. Against this attack, Elmar Seidel leapt to Riemann's defense, countering that Riemann regarded the slow movement of the Waldstein sonata as "one extended F-major cadential progression." It is noticeable, however, how Seidel has to strain Riemann's ideas to parry the charge. In fact, there are exceptionally few examples in Riemann's analytical writings that actually go beyond the eight-measure level. In other words, the organicist rhetoric in which Riemann deftly engages in his aesthetic writings, as we saw initially, praising the whole as more than the sum of its parts, is not carried out in his analytical endeavors, at least not in any ways that would be immediately apparent. In providing Riemann with a dualistic theory of form by exemplar, we have gone some steps toward redeeming the organicist promise that his aesthetics makes.

What used to be perceived as a weakness of the dualistic outlook on harmony, its fragmentary nature and its indecision over long-range tonal relations, however, may more recently have turned out to be the strength of this approach. It is not by coincidence that the various neo-Riemannian approaches came to the fore at exactly the same time as increasing dissatisfaction with the concept of musical autonomy, and the idealist work-concept, became widespread in musicological circles, and classic formalist positions came increasingly under attack. In a disciplinary reflection on the state of music analysis, however, Jim 
Samson has noted that neither formalism nor its broader cultural ally, modernism, "have been at all anxious to lie down and die." 54 Instead, the analytical project has had to be redefined. While for Samson a Barthesian "pleasure of the text" becomes an apposite defense of formalism, this is but one possible response to the recent challenges. Another one, it seems, is found precisely in Riemann's indecision that has now turned into a major advantage in the hands of neo-Riemannian theorists.

A number of features of Riemann's theoretical ideas have been forged into powerful analytical tools that seem to have captured the exigencies of this situation like no other theoretical approach. The neoRiemannian projects of recent years tend to be focused less on the analysis of complete works from beginning to end than on salient passages. Questions of tonality-a central concern of Riemann's own theorizing — have been relegated to the side lines. ${ }^{55}$ Similarly, following David Lewin's important insight that transformations are less interested in what chords are than in "how we get there," ${ }^{66}$ Riemann's architectonic conceptual framework has been modified in favor of a more processual (if not quite temporal) approach toward harmonic progressions. And much neo-Riemannian analysis has reveled in gleefully ignoring conventional formal models. 
Ironically, it was necessary to reconstruct the hypothetical nineteenth-century dualistic theory of form to become aware of the lack of one in the twenty-first. So far no work concept, in whatever post-modern guise, has coalesced with neo-Riemannian theories, but what seems to be beyond dispute is the fact that its necessarily fractured nature, ignoring or even defying totalities of any kind, makes it into the formal theory of our times.

\section{CAPTIONS}

Example 1: Riemann shows tonal relations in Beethoven's op. 18 no. 6 on his Tonnetz

Example 2: Johannes Brahms, Clarinet Trio, op. 114, I: Allegro, mm. $1-12$

Example 3: Riemann's "characteristic dissonances" in major (dominant seventh) and minor (subdominant "underseventh") are inversionally related

Example 4: Klangvertretung in the three key areas of the exposition:

E in three different significances

Example 5: Hauptmann's "chain of thirds" 
Example 6: First and second themes compared

Example 7: Second theme

Example 8: Harmonic motion of exposition demonstrated on Hauptmann's chain of thirds

Example 9; Functional shifts in the exposition

Example 10: Hauptmann's "triad of triads"

Example 11: Closing theme "getting stuck" on C\#/A\#

Example 12: Harmonic reduction of "short-circuited" circle of fifths in development section

Example 13: Riemann's Scheinkonsonanzen

Example 14: "Utopian" A-major variant of the third theme

Example 15: Dualistic synthesis along Hauptmann's chain of thirds

Example 16: Symmetric features in the exposition

Example 17: The equivalent passage in the recapitulation

Example 18: "Errant" cadences in the exposition

Example 19: Coda

Example 20: Harmonic content of recapitulation and code. Upper stems show "monistic" form while lower stems show "dualistic" synthesis

Example 21: Johannes Brahms, "Denn es gehet dem Menschen wie dem Vieh," from Four Serious Songs, opening

Example 22: Opening 12 measures 


\section{NOTES}

\footnotetext{
${ }^{1}$ I would like to thank Brian Hyer for his generous advice on an earlier draft of this essay. For a recent consideration of Riemann and musical forms see Scott Burnham, "Form," in Thomas Christensen, ed., Cambridge History of Western Music Theory (Cambridge: Cambridge
} University Press, 2002), pp. 880-906.

2 The extent to which Hauptmann can be considered a dualist is a matter of debate. Peter Rummenhöller vehemently denies it, as expounded in his "Moritz von Hauptmann, der Begründer einer transzendental-dialektischen Musiktheorie," Beiträge zur Musiktheorie im neunzehnten Jahrhundert, ed. Martin Vogel (Regensburg: Gustav Bosse, 1966), pp. 11-36. Still, the circumstance that subsequent dualists, above all Riemann, built on his work makes the question as to his true intentions a secondary issue.

${ }^{3}$ See Musikalische Syntaxis (Leipzig: Breitkopf und Härtel, 1877), pp. 104-111., where Riemann considers the key structures of multimovement works in terms of cadential "theses."

${ }^{4}$ Hugo Riemann, Systematische Modulationslehre (Hamburg: J. F.

Richter, 1887), p. 2. 
${ }^{5}$ For recent elucidations of Riemann's concepts of meter and functional harmony see Cambridge History of Western Music Theory, pp. $684-691$ and $796-800$.

${ }^{6}$ See Michael Arntz, Hugo Riemann (1849-1919): Leben, Werk, Wirkung (Cologne: Concerto-Verlag, 1999).

${ }^{7}$ In Große Kompositionslehre (Berlin and Stuttgart: W. Spemann, 1902), vol. 1, p. 424, Riemann spelled out that he was not interested in pursuing "the formal element beyond the eight-measure period." See also Lotte Thaler, Organische Form in der Musiktheorie des 19. und beginnenden 20. Jahrhunderts (Munich and Salzburg: Emil Katzbichler, 1984), esp. pp. 18-54.

${ }^{8}$ Scott Burnham, Beethoven Hero (Princeton, NJ: Princeton University Press, 1995), pp. 81-88. See also Thaler, Organische Form, p. 103.

${ }_{9}^{9}$ Riemann, Katechismus der Kompositionslehre (Berlin: Max Hesse, 1889), p. 95, and Große Kompositionslehre, vol. 1, pp. 477-8.

${ }^{10}$ Ibid., pp. 91-92.

${ }^{11}$ While it is well-known that his theory of function was presented in Vereinfachte Harmonielehre (1893), which was first published in English as Harmony Simplified, most of the functional terminology and concepts were first introduced two years earlier in an article, "Die Neugestaltung der Harmonielehre," Musikalisches Wochenblatt 22 
(1891), pp. 513-14, 529-31, 541-3. See also Renate Imig, Systeme der Funktionsbezeichnung in den Harmonielehren seit Hugo Riemann (Düsseldorf: Verlag zur Förderung der systematischen Musikwissenschaft, 1970).

12 Riemann, Katechismus der Kompositionslehre, p. 97.

${ }^{13}$ Riemann's "first form" corresponds to simple a A-B-A model (twopart song form), the "second form" to a somewhat larger A-B-A model, as in three-part song forms or minuet-and-trio, the "third form" to a more elaborate A-B-A model, as found in certain rondo forms, and the "fourth form" to sonata forms.

${ }^{14}$ Riemann, "Formen (musikalische)," in Musik-Lexikon, 4th edn (Berlin: Max Hesse, 1894), pp 310-311. The Musik-Lexikon is typically a useful source to follow up Riemann's ever-changing concepts; the fourth edition is chosen here as a standard because it was the first to be published after the important treatises Systematische Modulationslehre (1887) and Katechismus der Kompositionslehre (1889).

${ }^{15}$ Riemann, Katechismus der Kompositionslehre, p. 186.

16 Ibid., p. 189.

17 See Riemann, Musikalische Syntaxis, p. 105. 
${ }^{18}$ This was not the case in his harmony textbooks: by contrast, they were largely built on abstract harmonic examples, not from examples relating to actual pieces of music.

19 Thomas Christensen proposes some thoughts towards a formal "dialectic" on the basis of Riemann's theory of functions, in "The Schichtenlehre of Hugo Riemann," In Theory only 6 (1984), pp. 37-44. ${ }^{20}$ Brahms played an increasing role in Riemann's understanding of "healthy" music in the period of cultural pessimism in the years around 1900. Riemann explores his understanding of Brahms particularly in "Die Musik seit Wagners Heimgang: Ein Totentanz (1897)," in Präludien und Studien (Reprint Hildesheim: Georg Olms, 1967), vol. 2, pp. 33-41, and "Degeneration und Regeneration in der Musik," Max Hesses deutscher Musikerkalender 23 (1908), pp. 136-138 Margaret Notley has recently examined the role of Riemannian theoretical thought on Brahms, including analytical remarks on the Clarinet Trio, in "Plagal Harmony as Other: Asymmetrical Dualism and Instrumental Music by Brahms," Journal of Musicology (forthcoming).

${ }^{21}$ For a historiographic reflection that goes in a similar direction, see also Cristle Collins Judd, "The dialogue of past and present: Approaches to historical music theory," Intégral 14/15 (2000/01), pp. $1-7$. 
${ }^{22}$ Riemann was also a composer, whose oeuvre spans sixty-nine works. As far as I have been able to ascertain, however, not even Riemann's own compositions showed any signs of pure dualism. For a survey of Riemann's compositions, though with little reference to theoretical issues, see Michael Arntz, Hugo Riemann (1849-1919): Leben, Werk, Wirkung (Cologne: Concerto-Verlag, 1999), pp. 183-208.

${ }^{23}$ With apologies to Jean Baudrillard and the makers of The Matrix. ${ }^{24}$ See, for instance, Edwin Evans, Handbook to the chamber and orchestral music of Johannes Brahms (London: New Temple Press, s. a.), pp. 264-270, who has mainly scathing criticisms of a work he considers to be full of "weaknesses." The critical rejection that the Clarinet Trio received has recently been reviewed in Margaret Notley, “'Brain-Music' by Brahms: Toward an Understanding of Sound and Expression in the Allegro of the Clarinet Trio," American Brahms Society Newsletter 16 (1998), pp. 1-3.

${ }^{25}$ Michael Musgrave summarizes the form of the first movement in The Music of Johannes Brahms (Oxford: Oxford University Press, 1984), pp. 250-1.

${ }^{26}$ Both Margaret Notley and David Brodbeck comment on the absence of the leading note in this theme, see Notley "Plagal Harmony as Other," and Brodbeck, "Medium and Meaning: New Aspects of Chamber 
Music," in The Cambridge Companion to Brahms, ed. Michael Musgrave (Cambridge: Cambridge University Press, 1999), p. 128

${ }^{27}$ See System der musikalischen Metrik und Rhythmik (Leipzig:

Breitkopf und Härtel, 1903), p. 13.

${ }^{28}$ Peter H. Smith and Peter Foster both comment on this theme, noting that the clarinet entry, reversing the $\wedge 1$ and $\wedge 5$ of the theme in the cello, resembles a fugal comes. See Peter Foster, "Brahms, Schenker and the Rules of Composition: Compositional and Theoretical Problems in the Clarinet Works," PhD Dissertation (University of Reading, 1994), and Peter H. Smith, "Brahms and Subject/Answer Rhetoric," Music Analysis 20 (2001), pp. 193-236.

${ }^{29}$ See "Dissonanz: A. Charakteristische Dissonanz" in Musik-Lexikon, 5th edn (Berlin: Max Hesse, 1900). The term is not yet included in the 4th edn (1894), p. 239, although the underlying concept is clearly the same. Most of the relevant entries cited here are also translated in the glossary in my Hugo Riemann and the birth of modern musical thought (Cambridge: Cambridge University Press, 2003), pp. 186-198.

${ }^{30}$ Hermann von Helmholtz, On the Sensations of Tone, tr. Alexander J. Ellis (Reprint New York: Dover, 1954), p. 293.

${ }^{31}$ See "Klang," Musik-Lexikon, 4th edn (Berlin: Max Hesse, 1894), pp. $534-536$. 
${ }^{32}$ David Lewin, "A formal theory of generalized tonal functions," Journal of Music Theory 26 (1982), pp. 23-100.

${ }^{33}$ See James Webster, "Schubert's Sonata Form and Brahms' First Maturity," Nineteenth Century Music 2 (1978), pp. 18-35.

${ }^{34}$ See "Klangvertretung," Musik-Lexikon, p. 539.

${ }^{35}$ Peter $\mathrm{H}$. Smith also comments on the similarity between the two subjects, but examines it from a motivic viewpoint, see his "Btahms and the Shifting Barline: Metric Displacement and Formal Process in the Trios with Wind Instruments," Brahms Studies 3, ed. David Brodbeck (Lincoln, NE: University of Nebraska Press, 2001), p. 222.

${ }^{36}$ Riemann, Vereinfachte Harmonielehre (London: Augener, 1893), pp. 79-86.

37 Ibid., pp. 86-92.

${ }^{38}$ Riemann, Musikalische Logik (Leipzig: C. F. Kahnt, 1874), p. 42.

${ }^{39}$ Moritz Hauptmann, The Nature of Harmony and Metre, tr. W. E. Heathcote (Reprint New York: Da Capo Press, 1991), p. 8.

40 Ibid., p. 10.

${ }^{41}$ Ibid., pp. 10-14.

${ }^{42}$ I take the image of the "skipping needle" from Brian Hyer's article "Chopin and the in-F-able," in Raphael E. Atlas and Michael Cherlin, eds,. Musical Transformation and Musical Intuition: Eleven Essays in Honor of 
David Lewin (Roxbury, MA: Overbird Press, 1994), pp. 147-166, as it seems to describe precisely what goes on here. While in the corresponding place in the recapitulation the passage is not omitted, it is texturally completely integrated and does not stand out as a "scratch on the record."

${ }^{43}$ Riemann, “Sequenz," in Musik-Lexikon, p. 992.

${ }^{44}$ See Suzannah Clark, "Terzverwandtschaft in der Unvollendeten von Schubert und der Waldstein-Sonate von Beethoven - Kennzeichen des neunzehnten Jahrhunderts und theoretisches Problem," Schubert durch die Brille 20 (1998), pp. 122-130.

${ }^{45}$ See also Scott Burnham, "The Second Nature of Sonata Form," in Music Theory and Natural Order from the Renaissance to the Early twentieth Century (Cambridge: Cambridge University Press, 2001), pp. $111-141$

46 This idea can be found throughout Riemann's work, from Skizze zu einer neuen Methode der Harmonielehre (Leipzig: Breitkopf und Härtel, 1880), p. 18, onwards. Riemann's standard explanation for the prohibition of the major subdominant in the minor mode (and, correspondingly, the minor dominant in the major mode) is that the dualistic roots of the relevant chords would be more than one fifth apart, in other words no longer directly related. The pure mode of $A$ 
minor $\left({ }^{\circ} \mathrm{e}\right)$ is formed by ${ }^{\circ} \mathrm{a}-{ }^{\circ} \mathrm{e}-{ }^{\circ} \mathrm{b}$; to replace the subdominant with the its major variant would result in $\mathrm{d}^{+-^{\circ}} \mathrm{e}-{ }^{\circ} \mathrm{b}$, in other words two chords two fifths apart, which Riemann no longer considers a relation of the first degree.

${ }^{47}$ Smith, "Brahms and the Shifting Barline," pp. 191-229, discusses metric issues in the Clarinet Trio in some depth.

${ }^{48}$ See the preface to the 5 th edn of Handbuch der Harmonielehre (Leipzig: Breitkopf und Härtel, 1912), p. xvi.

${ }^{49}$ See David Lewin, "Amfortas' Prayer to Titurel and the role of D in Parsifal: The tonal spaces of the drama and the enharmonic $\mathrm{Cb} / \mathrm{B}$," first published in Nineteenth Century Music 7 (1984), pp. 336-349.

${ }^{50}$ This criticism of Riemann was made as early as 1878 , in Karl von Schafhäutl, "Moll und Dur," Allgemeine Musikalische Zeitung 13 (1878), cols. 1-137. For an exploration of this criticism see also Hugo Riemann and the Birth of Modern Musical Thought, Chapter 1.

${ }^{51}$ Again, this notion goes back to Judd's position paper, "The Dialogue of Past and Present," p. 7.

${ }^{52}$ See Suzannah Clark, "Seduced by notation: Arthur von Oettingen and the topography of dualistic musical space," in Suzannah Clark and Alexander Rehding, eds., Music Theory and Natural Order, pp. 161-180.

53 Judd, "The Dialogue of Past and Present," p. 6 
${ }^{54} \mathrm{Jim}$ Samson, "Analysis in Context" in Nicholas Cook and Mark Everist, eds., Rethinking Music (Oxford: Oxford University Press, 1999), p. 52.

${ }^{55}$ Of course there are considerable differences between individual approaches. See for instance, Steven Rings's recent dissertation. [CITE]

${ }^{56}$ Find reference. 